\title{
Analgesic Activity of Methanolic Extract of Tubers of Arisaema tortuosum (Wall.) Schott. in Swiss Albino Mice
}

\author{
Priyanka Chakraborty ${ }^{1}$, Nripendra Nath Bala ${ }^{1}$ and Sudipta Das ${ }^{2}$ \\ ${ }^{1}$ BCDA College of Pharmacy and Technology, Hridaypur, Barasat, Kolkata-700127, W.B, India \\ ${ }^{2}$ Netaji Subhas Chandra Bose Institute of Pharmacy, Chakdaha, Nadia-741222, W.B, India
}

(Received: 23 January, 2018; Accepted: 25 February, 2018; Published (web): 10 June, 2018)

\begin{abstract}
The aim of the the present study was to investigate the analgesic activity of methanolic extract of Arisaema tortuosum (MEAT) using acetic acid-induced writhing and hot plate methods. The hot plate method is useful in elucidating centrally mediated antinociceptive responses, while acetic acid-induced writhing is the chemically induced pain of peripheral origin. The MEAT was used at doses of 50, 100, 200 and $400 \mathrm{mg} / \mathrm{kg}$ body weight on swiss albino mice. The percentage inhibition of the abdominal constriction reflex increased dose dependently in case of acetic acid-induced pain and in the hot plate method model the extract at the dose of 400 $\mathrm{mg} / \mathrm{kg}$ significantly increased the pain reaction time (PRT). These studies conclude that A. tortuosum (Wall.) Schott. tuber possesses analgesic activity in a dose dependent manner. In case of acetic acid-induced pain, the extract at the dose of $400 \mathrm{mg} / \mathrm{kg}$ body wt. showed $41.19 \%$ inhibition of writhing reflex. In case of hot plate method, after 60 minutes the PRT increased to $7.47 \pm 0.05$ seconds for the extract at the dose of $400 \mathrm{mg} / \mathrm{kg}$ body wt.
\end{abstract}

Key words: Arisaema tortuosum, methanolic extract, pain, hot plate method, writhing test.

\section{INTRODUCTION}

Pain is an unpleasant sensory and emotional experience associated with actual or potential tissue damage, or described in terms of such damage. It is always a warning signal and primarily protective in nature but often causes a lot of discomfort and lead to many adverse effects. ${ }^{1}$ Analgesics are drugs used to treat or reduce pain and the classical analgesic drugs notably opiates and non-steroidal anti-inflammatory drugs have their origin in natural products but many synthetic compounds that act by the same mechanism have been developed and are associated with serious adverse effects such as ulceration, gastrointestinal bleeding, additive potential, respiratory distress, drowsiness, nausea etc. ${ }^{2}$

Arisaema tortuosum (Wall.) Schott. belongs to the family Araceae. This is commonly called whipcord cobra lily and by many other names in the Indian subcontinent (Chinese: qu xu nan xing •

Correspondence to: Priyanka Chakraborty

E-mail: priyanka290986@gmail.com

Dhaka Univ. J. Pharm. Sci. 17(1): 37-41, 2018 (June)
Hindi: kiri ki kukri, samp ki kumbh, Bagh Jandhra • Kannada: haavu mari gida - Konkani: sarpache kamdo - Marathi: sapkanda - Nepalese: bir bango • Tamil: katu cenai). The name comes from its cobra like appearance, with a whip-like tongue, upto 12 inches long, rising up vertically. Native to open Rhododendron forests, scrub and alpine meadows in the Himalaya from India to western China. The thick 4 feet tall fleshy petiole (stalk) emerges in early June, adorned by two tropical looking palmate green leaves near the top. As the leaves unfurl, the pitcher that tops the stem opens to reveal a green Jack-in-thepulpit flower, but with a whip-like tongue that extends from the mouth of the flower upwards to 12 or more inches. In autumn, bright red berries ripen on the tall stem of those plants that have set seed. This wonderful plant for the woodland garden starts out about $50 \mathrm{~cm}$ tall, but it can eventually attain $2 \mathrm{~m}$ and form large clumps. It is highly variable, as one might expect. Sometimes, the spadix-appendage is green, other times it is purple. ${ }^{3}$ 
Different parts of this herb have been used in folkloric medicine for treatment of various ailments related to digestive tract like constipation, indigestion, abdominal pain, dysentery and helmenthiasis. Paste of the tuber is applied over the wound caused by snake bite to check poisonous effect. In case of abscess in the neck, dried powder of tuber is applied over the neck. It helps in early healing. The decoction of tuber is given to animals for early recovery of fractured bone. The tuber also used for antinematodal purpose. Powder of one tuber is divided in three parts and each part is taken orally daily for three days to cure liver complaints and stomachache. $^{4}$

The present study was therefore undertaken to investigate the analgesic activity of the tuber of A. tortuosum with the aim of establishing the pharmacological basis for its folkloric use to treat pain.

\section{MATERIALS AND METHODS}

Plant collection and identification. The plant A. tortuosum was collected in the month of July 2016 from Darjeeling district of West Bengal, India. The taxonomical identification of the plant was done by Botanical Survey of India, Shibpur, India and the voucher specimen (BCDAPT/Priyanka/2015-16/01) has been preserved in Pharmacology Research Laboratory, BCDA College of Pharmacy and Technology for future references.

Preparation of plant extract. The tubers of A. tortuosum were dried under shade and then powered with mechanical grinder. The powder plant material was extracted with methanol through maceration. The solvent was removed by rotary evaporator and semisolid mass was obtained (yield $11.30 \% \mathrm{w} / \mathrm{w}$ ). The extract was stored in vacuum desiccators for further use.

Chemicals. Dichlofenac sodium $(20 \mathrm{mg} / \mathrm{kg})$ and pentazocine $(10 \mathrm{mg} / \mathrm{kg})$, acetic acid $(0.6 \% \mathrm{v} / \mathrm{v})$, MEAT, normal saline and other chemicals were of analytical grade.

Animals. Swiss male albino mice (age: 4-5 weeks and weight: 25-35 g) were housed in animal unit of BCDA College of Pharmacy and Technology under standard laboratory conditions (temperature 23 $\pm 2^{\circ} \mathrm{C}$ ) with $12 \mathrm{~h}$ dark and $12 \mathrm{~h}$ light cycle. The animals had free access to standard dry pellet diet and tap water ad libitum. The experiments were performed with subject to minimum pain to the experimenting animals. All the ethical considerations have been followed. The research was conducted in accordance with the ethical rules on animal experimentation, approved by Ethical Committee, BCDA College of Pharmacy and Technology (Approval No: 1682/PO/a/13/CPCSEA).

Acute toxicity study. Acute oral toxicity of methanolic extracts of tubers of A. tortuosum was determined by using female, nulliparous and non pregnant mice weighing 18-22 g. The animals were fasted for $3 \mathrm{hrs}$ prior to the experiment. Up and down procedure OECD guideline no. 425 was adopted for toxicity studies. Animals were administered with single dose (2000 mg/kg body weight) of extract and observed for their mortality during 14 days study period. $^{5}$

\section{Analgesic activity}

Acetic acid-induced writhing test. Acetic acid-induced writhing test was performed as reported previously. ${ }^{6}$ Briefly, mice were treated with diclofenac sodium $(20 \mathrm{mg} / \mathrm{kg}$ body wt., i.p.), a standard analgesic drug, MEAT and the vehicle 30 min before intra-peritoneal injection of $0.6 \%, 10$ $\mathrm{ml} / \mathrm{kg}$ body weight acetic acid. Number of abdominal constrictions i.e. writhes were counted for each group of mice starting from 5 minutes after the injection of acetic acid up to 20 minutes and expressed as percent protection. The percentage protection against acetic acid was calculated using the following formula:

$$
\% \text { Inhibition }=\left\{\left(\mathrm{N}_{\mathrm{c}}-\mathrm{N}_{\mathrm{t}}\right) / \mathrm{N}_{\mathrm{c}}\right\} \times 100
$$

where $\mathrm{N}_{\mathrm{c}}$ is number of writhings in control, and $\mathrm{N}_{\mathrm{t}}$ is the number of writhings in test animals ${ }^{7}$

Hot plate test. This is one of the most commonly used methods for evaluating central analgesic activity of a drug. In this method heat was used as a source of pain. Mice were divided into 6 groups of six each. First group served as a control, 
second group served as the standard (Pentazocine 10 $\mathrm{mg} / \mathrm{kg}$ body wt, intraperitoneally), while the third, fourth, fifth and sixth groups received 50,100, 200 and $400 \mathrm{mg} / \mathrm{kg}$ of MEAT respectively. After 1 hour, animals were individually placed on a hotplate maintained at a temperature of $55 \pm 0.5^{\circ} \mathrm{C}$, and were placed not more than 15 seconds (cut off time) on the hotplate, in order to avoid damage to the paws. The time taken to flick the hind paw or lick or jump from the hot plate was considered as the reaction time of the particular animal. The reaction time was recorded at $0,15,30$ and $60 \mathrm{~min}$ interval. . An analgesic increases the reaction time. Percent decrease in reaction time was taken as index of pain perception at each interval. ${ }^{8}$

Statistical analysis. The data of the analgesic activity by number of writhes and tail flicks were expressed as mean \pm SEM of six animals in each group. The statistical analysis was carried out using one-way ANOVA followed by Tukey's t-test. The difference in values at $\mathrm{p}<0.05$ was considered as statistically significant.

\section{RESULTS AND DISCUSSION}

Acute toxicity test. Acute toxicity test of the extract produced no death or signs of toxicity after 24 hours even at the dose of $2000 \mathrm{mg} / \mathrm{kg}$ body wt. which shows that the extract was well tolerated.

Acetic acid induced writhing reflex. The methanolic extract of the plant $A$. tortuosum rhizomes at the doses of 50,100, 200 and $400 \mathrm{mg} / \mathrm{kg}$ body weight and dichlofenac sodium $(20 \mathrm{mg} / \mathrm{kg}$ body weight) induced significant decrease (5.96, 25.57, $26.98,41.19$ and $68.46 \%$ ) in the number of writhes when compared to control groups. The four doses tested (50,100, 200 and $400 \mathrm{mg} / \mathrm{kg}$ body weight) produced significant analgesic activity. Results of acetic acid induced writhing has been shown in table 1 .

Table 1. Acetic acid induced writhing reflex.

\begin{tabular}{llcc}
\hline Group & Treatment & $\begin{array}{c}\text { Mean number of writhing } \pm \text { s.e. } \\
\text { m.(n=6) }\end{array}$ & \% Inhibition \\
\hline A & Control & $58.66 \pm 0.33$ & - \\
B & Dichlofenac Sodium $(20 \mathrm{mg} / \mathrm{kg} \mathrm{BW})_{\mathrm{C}}$ & $18.50 \pm 1.10$ & 68.46 \\
$\mathrm{C}$ & $\mathrm{MEAT}_{50}$ & $55.16 \pm 0.64$ & 5.96 \\
$\mathrm{D}$ & $\mathrm{MEAT}_{100}$ & $43.66 \pm 0.66$ & 25.57 \\
E & $\mathrm{MEAT}_{200}$ & $42.83 \pm 0.99$ & 26.98 \\
F & MEAT $_{400}$ & $34.50 \pm 1.92$ & 41.19 \\
\hline
\end{tabular}

* $\mathrm{p}<0.05$ when compared with control group; statistically analysis was evaluated by Dunnett's vs. control. .

Hot plate method. The result shows that there was no significant difference in the latency during the pre drug testing time. After drug and extract administration, comparing the pre and post drug latency using t-test showed that the reference drug pentazocine $(10 \mathrm{mg} / \mathrm{kg}$ body wt.) and the methanolic extract of the plant $A$. tortuosum at the doses of 50, 100,200 and $400 \mathrm{mg} / \mathrm{kg}$ body wt. significantly increased the latency. Results of acetic acid induced writhing reflex are shown in table 2 .

Two antinociceptive models, acetic acid induced writhing reflex and hot plate models were used to evaluate the analgesic activity of methanolic extact of tubers of A. tortuosum since tests of analgesic drugs commonly measure nociception and involves the reaction of animals to painful stimuli. The stimulus may be thermal (hot plate tests), chemical (acetic acid-induced writhing or formalin tests) or mechanical (tail or paw pressure tests). ${ }^{9}$ The methanolic extract of tubers of A. tortuosum produced no death or signs of toxicity even at the dose of $2000 \mathrm{mg} / \mathrm{kg}$ body weight which suggests that the extract was well tolerated by the mice and that the doses used were safe. 
Table 2. Effect of A. tortuosum and standard drug in hot plate method.

\begin{tabular}{|c|c|c|c|c|c|}
\hline Group & Treatment & $\begin{array}{l}\text { Before treatment } \\
\pm \text { S.E.M. }(\mathrm{n}=6)\end{array}$ & $\begin{array}{l}\text { After treatment } \\
\quad(15 \text { mins }) \\
\pm \text { S.E.M. }(\mathrm{n}=6)\end{array}$ & $\begin{array}{l}\text { After treatment } \\
\quad(30 \text { mins }) \\
\pm \text { S.E.M. }(n=6)\end{array}$ & $\begin{array}{l}\text { After treatment } \\
\quad(60 \text { mins }) \\
\pm \text { S.E.M. }(n=6)\end{array}$ \\
\hline A & Control & $2.16 \pm 0.01$ & $2.65 \pm 0.17$ & $2.56 \pm 0.15$ & $2.77 \pm 0.11$ \\
\hline B & Pentazocine $(10 \mathrm{mg} / \mathrm{kg}$ bw) & $2.26 \pm 0.01$ & $5.52 \pm 0.10$ & $6.11 \pm 0.11$ & $8.78 \pm 0.05$ \\
\hline $\mathrm{C}$ & $\operatorname{MEAT}_{50}$ & $2.25 \pm 0.03$ & $3.23 \pm 0.03$ & $3.49 \pm 0.10$ & $4.44 \pm 0.13$ \\
\hline $\mathrm{D}$ & $\operatorname{MEAT}_{100}$ & $2.24 \pm 0.01$ & $3.27 \pm 0.02$ & $4.57 \pm 0.16$ & $5.36 \pm 0.03$ \\
\hline $\mathrm{E}$ & $\operatorname{MEAT}_{200}$ & $2.22 \pm 0.01$ & $4.74 \pm 0.14$ & $5.30 \pm 0.04$ & $6.31 \pm 0.07$ \\
\hline $\mathrm{F}$ & $\operatorname{MEAT}_{400}$ & $2.27 \pm 0.02$ & $5.29 \pm 0.05$ & $5.28 \pm 0.04$ & $7.47 \pm 0.05$ \\
\hline
\end{tabular}

*p $<0.05$ when compared with control group; statistically analysis was evaluated by Dunnett's vs. control.

Acetic acid induced writhing reflex is a model of visceral pain which is highly useful for screening analgesic drugs and several chemicals such as phenylquinine and acetic acid could induce writhing reflex in laboratory animals. Intraperitoneal injection of $0.6 \%$ glacial acetic acid produced abdominal writhing in this experiment. Acetic acid produces writhing reflex in animals by activating the chemo sensitive nociceptors. ${ }^{10}$ Also, it has been noted that the level of analgesia in acetic acid-induced models is indicated by the percent reduction in the number of abdominal constrictions. In this experiment, the reference drug and A. tortuosum extract at 100, 200 and $400 \mathrm{mg} / \mathrm{kg}$ body wt significantly decreased the mean number of abdominal constrictions or writhes which was dose dependent. The extract showed no inhibition against the acetic acid induced writhing in the control group, where the inhibition increased to $41.19 \%$ at the dose of $400 \mathrm{mg} / \mathrm{kg}$. The analgesic effect of A. tortuosum seen in this experiment may be mediated through peripheral pain mechanism and or through suppression of prostaglandin pathway since it has been observed that any agent that decreases the number of writhing will demonstrate analgesia preferably by inhibition of prostaglandin synthesis, a peripheral mechanism of pain inhibition. ${ }^{11}$ The above results showed that the inhibition increased in the extract treated group which was found to be significant $(\mathrm{p}<0.05)$ for all the concentrations as compared to control group.

In the hot plate model, comparing the latency pre and post treatment, the extract at the doses of 200 and
$400 \mathrm{mg} / \mathrm{kg}$ significantly increased the pain reaction time and the extract at the dose of $400 \mathrm{mg} / \mathrm{kg}$ had a better analgesic effect than other groups which was expected in this model. The above results showed that the increase in reaction time in the extract treated group was found to be significant after 15, 30 and $60 \mathrm{~min}(\mathrm{p}<0.05)$ as compared to control group.

The hot plate method has been used to study centrally acting analgesic activity. ${ }^{12}$ In these models, sensory nerves sensitise the nociceptors and the involvement of endogenous substances such as prostaglandins are minimised..$^{12}$ From the results, though the extract showed analgesic actions in hot plate models, it was more pronounced as seen in the acetic acid-induced model and this may suggest that the analgesic activity of $A$. tortuosum may be fully mediated through central mechanism. ${ }^{13}$

In conclusion, the methanolic tuber extract of $A$. tortuosum demonstrated significant analgesic activity and may be acting through inhibition of prostaglandin pathway and or through peripheral pain mechanism. However, more work is required in the isolation and characterisation of the bioactive compound(s) and determination of the exact mechanism of action.

\section{Conflict of interest}

The authors declared no conflict of interest.

\section{REFERENCES}

1. Lalan, B.K., Hiray, R.S. and Ghongane, B.B. 2015. Evaluation of analgesic and Anti-inflammatory activity of extract of Holoptelea integrifolia and Argyreia speciosa in snimal models. J. Clini. Diagnostic Res. 9, 1-4. 
2. Stucky, C.L., Gold, M.S. and Zhang, X. 2001. Mechanisms of pain. Proc. Natl. Acad. Sci. 98, 11845-11846.

3. Verma, H., Lal, V.K., Pant, K.K. and Soni N. 2012. A ethnomedicinal review on Arisaema tortuosum. IJAPBC. 1, 176-179

4. Temponi, V.D.S., Da, Silva, J.B., Alves, M.S., Ribeiro, A., De Pinho, J.R.G., Yamamoto, C.H., et al. 2012. Antinociceptive and anti-inflammatory effects of ethanol extract from Vernonia polyanthes leaves in rodents. Int. J. Mol. Sci. 13, 3887-3899.

5. OECD. OECD guidelines for the testing of chemicals, acute oral toxicity- up-and-down-procedure (UDP). 425.2008: 27. Adopted Oct 03, 2008.

6. Siva, P. P., Nilanjan S., Sudipta D., Asis B. and Pallab K. H. 2015. Evaluation of analgesic and anti-inflammatory activity of methanol extract of Cucumis callosus roots in animal models. Pharmacologia 7, 283-289.

7. Aoki, M., Tsuji, M., Takeda, H., Harada, Y., Nohara, J., Matsumiya, T. and Chiba, H. 2006. Antidepressants enhance the antinociceptive effects of carbamazepine in the acetic acid-induced writhing test in mice. Europ. J. Pharmacol. 550, 78-83.
8. Kumae, G.S., Rajesh, K. and Sengottuvelu, S. 2011. Evaluation of analgesic and anti inflammatory activity of methanolic extract of Cocculus hirsutos leaves. Int. Res. J. Pharm. 2, 230-234.

9. George, K.A., Eric, W., David, D.O. and George, A.K. 2009. Antinociceptive effects of Newboulia Laveis (P. Beauv) stem bark extract in rat model. Pharmacog. Mag. 17, 49-54.

10. Onasanwo, S.A., Elegbe, R.A. 2006. Antinociceptive and anti-inflammatory properties of the leaf extract of Hedranthera barteri in rats and mice. African J. Biomed. Res. 2, 109-118.

11. Ferdous, M., Rouf, R., Shilpi, J.A. and Uddin S.J. 2008. antinociceptive activity of the ethanolic extract of Ficus racemosa (Lin). Oriental Pharm. Exp. Med. 8, 93-96.

12. Franzotti, E.M., Santos, C.V.F., Rodrigues, H.M.S., Mourao, R.H.V. and Andrade, M.R. 2000. Anti-inflammatory, analgesic and acute toxicity of Sida cordiforlia L. J. Ethnopharmacol. 72, 273-277.

13. Bentley, G. A., Newton, S. H. and Starr, J. 1983. Studies on the antinociceptive action of $\alpha$-agonist drugs and their interactions with opioid mechanisms. British J. Pharmacol. 79, 125-134. 